\title{
Workshop para avaliação da situação epidemiológica da filariose linfática no Município de Belém, Pará, norte do Brasil
}

\author{
Workshop to evaluate the epidemiologic situation of lymphatic filariasis in the \\ Municipality of Belém, Pará, Northern Brazil
}

Belém, PA, 2 a 4 de maio de 2005

\section{Helen Freitas ${ }^{1}$, João Batista Vieira1 ${ }^{1}$, Reinaldo Braun ${ }^{2}$, Zulma Medeiros ${ }^{3}$, Eliana Maria M. Rocha ${ }^{4}$, Ana Aguiar-Santos ${ }^{3}$, Habib Fraiha ${ }^{5}$ e Abraham Rocha ${ }^{3}$}

A Força Tarefa Internacional para Erradicação de Doenças, de 1993, considerou a filariose linfática (FL) como uma das seis doenças infecciosas erradicáveis ou potencialmente erradicáveis. Em 1996, o Special Programme for Research and Training in Tropical Diseases elegeu a FL como uma das quatro doenças que receberiam suporte para sua eliminação mundial como um problema de saúde pública9 . Entendendo eliminar como problema de saúde pública como a interrupção da transmissão. A Organização Mundial da Saúde (OMS) em assembléia ocorrida em maio de 1997, conclamou, mediante a resolução 50.29, para a adoção da meta de eliminação global da filariose linfática até o ano $2020^{10}$. O Brasil tornou-se signatário dessa proposta ainda em $1997^{3}$, criando o Programa Nacional para Eliminação da Filariose Linfática (PNEFL), cujas atividades foram respaldadas pela resolução 190/96 do Conselho Nacional de Saúde.

O Programa Nacional tem entre seus fundamentos a intervenção nos locais com transmissão da doença, e a certificação de eliminação nas áreas onde considera-se que tenha havido a interrupção da transmissão. Entretanto, o conhecimento obtido sobre FL ao longo dos anos não permitiu, até o momento, determinar claramente quais critérios são necessários para assegurar que uma área endêmica teve a transmissão dessa doença interrompida ${ }^{13}$. Assim, os indicadores para certificar a eliminação da transmissão não estão definitivamente estabelecidos. Por outro lado, assumir que um determinado foco está eliminado, e que as atividades de combate a essa doença podem ser interrompidas, tem implicações práticas imediatas, visto que estas atividades envolvem onerosos custos além das dificuldades específicas para sua execução. Por esse motivo, no âmbito mundial, e diante da lacuna em relação aos indicadores, certos países têm assumido alguns critérios próprios, admitindo que a transmissão está interrompida em suas áreas endêmicas. A China, por exemplo, determinou que a transmissão está eliminada em seu território. Para essa assunção, técnicos chineses levaram em conta vários dados epidemiológicos da doença além de informações sócio ambientais sobre seu país ${ }^{12}$.

A Cidade de Belém, no Estado do Pará, foi um dos maiores focos de FL identificados no Brasil. As taxas de prevalência de parasitados entre os examinados atingia 18\%. Durante quatro décadas, medidas foram adotadas com o objetivo de combater o problema, modificando substancialmente o perfil epidemiológico da doença naquela cidade. Ainda na década de 1950, foram implantadas consistentes estratégias de combate à doença que se mantiveram em quantidade e qualidade até $o$ início dos anos 2000. Esses aspectos transformaram o foco de FL de Belém em campo ideal para estudo do comportamento epidemiológico dessa doença frente às medidas de combate particularmente no que se refere aos indicadores de eliminação.

No ano de 2002, como um caminho na busca pela comprovação da eliminação do foco de Belém, A Organização Pan Americana de Saúde (OPAS) e o Ministério da Saúde (MS), com apoio do Centro de Pesquisa Ageu Magalhães/PE e Universidade Federal de Alagoas/UFAL, propuseram estudos epidemiológicos com o objetivo de reforçar as informações obtidas a partir dos dados da Secretaria Municipal de Saúde de Belém (SMS/Belém). Foram realizados inquéritos em amostras da população, dois

\footnotetext{
1. Coordenação de Doenças Transmitidas por Vetores, Serviço de Vigilância Sanitária, Ministério da Saúde, Brasília, DF. 2. Secretaria Municipal de Saúde de Belém, Belém, PA. 3. Departamento de Parasitologia, Serviço de Referência Nacional em Filariose, Centro de Pesquisas Aggeu Magalhães, Fundação Oswaldo Cruz, Recife, PE. 4. Instituto de Ciências Biológicas e da Saúde, Universidade Federal de Alagoas, MAceió, AL. 5. Universidade Federal do Pará, Belém, PA.

Endereço para correspondência: Prof. Abraham Rocha. Depto de Parasitologia/CPqAM/FIOCRUZ. Av. Moraes Rego s/n, 50670-420 Recife, PE.

Tel: 5581 2101-2500

e-mail: rocha@cpqam.fiocruz.br

Recebido para publicação em: 22/08/2007

Aceito em: 07/03/2008
} 
deles apoiados em pesquisa de antígeno filarial em humanos, um levantamento sobre morbidade filarial e ainda uma pesquisa, por meio do exame PCR, sobre níveis de infecção vetorial.

o Workshop de que trata este relatório, realizado no Núcleo de Medicina Tropical da Universidade Federal do Pará, de 2 a 4 de maio de 2005, teve três objetivos:

1. Reunir todos os dados disponíveis sobre o foco de FL de Belém, incluindo-se dados de serviço e resultado dos estudos;

2. Consolidar esses dados e, a partir daí, avaliar se nas informações geradas havia suficiente evidência de que o foco de Belém teve sua transmissão interrompida; mesmo levando em conta o fato de não haver uma padronização de critérios estabelecida pela OPAS/OMS;

3. Finalmente, a partir dessa avaliação, considerar o foco eliminado ou não. No caso positivo, estabelecer entre os vários aspectos analisados aqueles que satisfariam as condições para se afirmar, de um modo geral, que um foco de FL está eliminado. Nesse caso, prestar uma contribuição à OPAS/OMS para a validação dos parâmetros que confirmam a interrupção da transmissão.

\section{A SITUAÇÃO EPIDEMIOLÓGICA DA FILARIOSE LINFÁTICA NA CIDADE DE BELÉM/PA, NO PERÍODO DE 1940-1950}

\section{Prof. Habib Fraiah Neto}

Os primeiros estudos sobre a ocorrência de FL em Belém datam da década de 1940, quando foram examinadas, por meio de hemoscopia, 5.000 pessoas e detectada a infecção por Wuchereria bancrofti em 10,8\% delas. Um estudo semelhante, realizado em 1945, mostrou taxas de prevalência entre examinados de 11,6\%, confirmando aquela área como foco da endemia. Na época, Belém apresentava condições ambientais ideais para a instalação dessa endemia, entre elas, temperatura elevada, índices pluviométricos altos, precário saneamento básico. Esses aspectos propiciam uma alta densidade vetorial que por sua vez favorece, de forma expressiva, o aumento da transmissão. Na década de 1950, o MS realizou um inquérito nacional que mostrou Belém como o município com a segunda maior prevalência detectada, chamando $a$ atenção para a necessidade de intervenção naquela área ${ }^{27}$.

\section{A SITUAÇÃO EPIDEMIOLÓGICA DA FILARIOSE LINFÁTICA NA CIDADE DE BELÉM/PA, NO PERÍODO DE 1960-2004}

\section{Expositor: Dr. Reinaldo Braun}

Após os inquéritos da década de 1950, foi estabelecido um consistente programa de triagem populacional, por meio de exames hemoscópicos, com o propósito de detectar e tratar os portadores de microfilária. Essa intervenção visava reduzir as fontes de transmissão e ainda fornecer informações para o acompanhamento da situação epidemiológica da doença. Assim, anualmente, uma parcela da população de Belém era submetida a exames hemoscópicos e entre os anos de 1951 e 1994 realizaram-se 11.487 .047 exames. 0 pico de atividade ocorreu nos anos 1970, quando cerca de $80 \%$ das pessoas residentes naquela cidade foram anualmente examinadas. Nessa época, a prevalência entre os examinados reduziu-se a menos de 1\%. Para execução dessa ação, realizavam-se buscas de pessoas casa a casa para exame, e tratamento sob supervisão dos casos positivos. Foi utilizada a droga dietilcarbamazina (DEC) com a posologia preconizada pela OMS.

A partir de 1995, incorporou-se como atividade rotineira a avaliação de todos os familiares dos casos positivos detectados, bem como dos indivíduos residentes, em um raio de pelo menos 100 metros do domicílio dos casos. No período de 1995 a 2003 realizaram-se 1.116 .525 exames, investigando-se cerca de $41 \%$ da população residente em 81 bairros de Belém. Essas triagens evidenciaram uma queda consistente e sistemática na detecção de casos, não havendo identificação de microfilariêmicos a partir de 1999, exceto no ano de 2001 com a identificação de um individuo positivo ${ }^{2}$.

\section{AVALIACCÃO DA OCORRÊNCIA DE FILARIOSE LINFÁTICA EM MUNICÍPIOS CONTÍGUOS A BELÉM/PA}

\section{Dr. Reinaldo Braun}

Para conhecer o perfil epidemiológico da FL nos municípios contíguos à Belém, realizaram-se inquéritos em Ananindeua, Benevides, Vigia, Abaetuba, Bacarena, Salvaterra, Soure, IgarapéMirim e Cametá. Em Ananindeua, município conurbado à Belém, examinaram-se, por meio de hemoscopia, 2.713 pessoas distribuídas em 18 setores censitários, todas com resultados negativos. Nos outros municípios, foram examinadas 18.713 pessoas, distribuídas em 75 setores censitários, também com todos os resultados negativos.

\section{IDENTIFICAÇÃO DE ÁREAS COM MAIOR RISCO DE TRANSMISSÃO DE FILARIOSE LINFÁTICA NO MUNICÍPIO DE BELÉM/PA}

\section{Prof ${ }^{\mathrm{a}}$ Zulma Medeiros}

Aidentificação de áreas com perfil sócio ambiental que favorece a transmissão da FL tem sido realizada mediante a aplicação de um indicador de risco, neste caso chamado indicador sintético de risco (ISR). Esse indicador relaciona aspectos referentes ao meio ambiente e situação sócio-econômica, atribuindo escores a cada um deles. Entre esses itens estão abastecimento de água, esgotamento sanitário, coleta de lixo, renda familiar e instrução do chefe da família 5 .

Como parte da avaliação da situação da FL em Belém, calculou-se ISR, para identificar, dentro deste município, os setores censitários que apresentam maior risco de transmissão da FL. Belém possui 1.179 setores censitários, o ISR mostrou 295 destes como de alto risco, correspondendo a 61 bairros ou localidades. Essa informação foi usada na priorização das áreas onde seriam realizados os estudos propostos pela OPAS e MS. 
PESQUISA SOBRE A PREVALÊNCIA DE ANTÍGENO FILARIAL, POR MEIO DE TESTE RÁPIDO DE DIAGNÓSTICO, CARTÃO DE ICT (IMUNOCROMATOGRÁFICO), EM POPULAÇÃO DE ESCOLARES RESIDENTES NO MUNICÍPIO DE BELÉM/PA

\section{Dr. Reinaldo Braun}

A prevalência de antígeno filarial em crianças de 6 a 10 anos oferece informação sobre o perfil de transmissão de FL em uma determinada comunidade ${ }^{11}$. Assim, no ano de 2002 realizou-se um estudo para determinar a prevalência de antígeno circulante de Wuchereria bancrofti, mediante uma amostra da população de escolares residentes nos bairros que tiveram microfilariêmicos detectados durante a década de 1990. As crianças foram examinadas pelo método da imunocromatografia usando cartões ICT. Para a determinação da amostra selecionaram-se aleatoriamente 15 escolas, de um total de 25 existentes nesses bairros. Examinaram-se 3.000 escolares com idade de 6 a10 anos, correspondendo a $40 \%$ do total de alunos nessa faixa etária. Todos os resultados foram negativos ${ }^{1}$.

PESQUISA SOBRE A PREVALÊNCIA DE ANTÍGENO FILARIAL, POR MEIO DE TESTE RÁPIDO DE DIAGNÓSTICO, CARTÃo DE ICT (IMUNOCROMATOGRÁFICO), EM HOMENS RESIDENTES NO MUNICÍPIO DE BELÉM/PA

\section{Prof. Abraham Rocha}

A literatura aponta os homens com idade de 20 a 30 anos como a população de maior risco de infecção pela Wuchereria bancrofti 5 . Apoiado nessa informação, realizou-se um inquérito de prevalência de antígeno filarial em homens nessa faixa etária, adotando-se assim uma amostra de conveniência. A eleição dos setores censitários para o estudo teve como base o histórico de prevalência de FL e as informações oferecidas pelo ISR. Assim, foram selecionados 75 setores censitários de Belém, dez dos quais pelo critério de história de casos de FL até a década de 1990, outros 10 exclusivamente pelo critério do ISR e os restantes pela concomitância desses critérios. Nessas áreas realizou-se um levantamento do número de residentes homens com idade de 20 a 30 anos, dos quais, foi retirada uma parcela para a pesquisa. De um total 7.367 homens identificados, foram coletados exames de 2.816 deles, escolhidos aleatoriamente. 0 exame foi realizado por meio de cartão de ICT. O inquérito antigênico nessa população também não detectou qualquer caso de $\mathrm{FL}^{8}$.

\section{INQUÉRITO SOBRE A INFECÇÃO VETORIAL, USANDO A TÉCNICA DE PCR, NO MUNICÍPIO DE BELÉM/PA}

Prof ${ }^{\mathrm{a}}$ Eliana Maria M. Rocha

Nas casas das pessoas que realizaram exames hemoscópicos nos anos de 2002 e 2004, foram coletados mosquitos vetores para exame. Em 2002, a captura foi manual e foram coletados 9.100 mosquitos. A partir de 2003, adotou-se a técnica de xenomonitoramento, quando foram coletados 21.900 espécimes. Foram também coletados mosquitos nas casas de todos os homens participantes do inquérito com cartão ICT, um total de 9.800 mosquitos. Assim foram capturados, de 2002 a 2004, 40.800 mosquitos. Amostras de DNA extraídas destes mosquitos foram analisadas pela técnica de PCR para a infecção por Wuchereria bancrofti. Todos tiveram resultado negativo.

\section{INQUÉRITO PARA DETECÇÃO DE PESSOAS PORTADORAS DE MORBIDADE FILARIAL EM BAIRROS DO MUNICÍPIO DE BELÉM/PA}

Dra Ana Maria Aguiar-Santos

A presença de pessoas portadoras de morbidade filarial, em especial a hidrocele, é um importante indicador da ocorrência de $\mathrm{FL}^{4}$. Em Belém, realizou-se um inquérito com objetivo de identificar, mediante queixas referidas, a presença de pessoas com manifestações clínicas que poderiam estar relacionadas à morbidade filarial. Nos 75 setores censitários considerados de alto risco para filariose, entrevistaram-se 9.645 pessoas, todas residentes nos mesmos domicílios dos homens que foram submetidos à investigação com cartões ICT. Identificaram-se 28 pessoas com queixa referida. Dessas 18 relataram erisipela, três hidrocele, duas urina leitosa e uma referiu linfedema.

\section{CRITÉRIOS PARA CERTIFICAÇÃo DA ELIMINAÇÃo DA FILARIOSE BANCROFTIANA.}

\section{Prof. David Addiss}

Embora a OMS tenha proposto, em 1997, a eliminação da filariose linfática como um problema de saúde pública, ainda não estão validados os indicadores para sua certificação. Dessa forma, os países que consideram que a transmissão da FL está interrompida em seus focos endêmicos não dispõem de um roteiro comum a ser seguido para certificar essa condição. 0 estabelecimento desses critérios deverá ser discutido ainda esse ano na reunião do WHO Technical Advisory Group (TAG). Entretanto, em caráter provisório, os países poderão seguir o modelo de verificação adotado pela China. 0 modelo adotado pelos chineses se apóia em um amplo levantamento de dados epidemiológicos passados e atuais sobre seus focos, acrescido de informações demográficas, incluindo sobre migração, ambientais, e outros fatores que influenciam a manutenção dos focos e transmissão da doença. Uma adaptação do modelo chinês foi apresentada. Essa adaptação foi sugerida como um pré-roteiro para a elaboração de um documento solicitando ao TAG/OMS a certificação da eliminação do foco de Belém, embora o procedimento adotado pela OMS seja de certificação de eliminação no âmbito de país e não de foco.

INQUÉRITO VETORIAL COMO ESTRATÉGIA DE MONITORAMENTO DO IMPACTO DOS PROGRAMAS DE COMBATE À FILARIOSE LINFÁTICA

Prof. Dave Chade 
Como sugestão para o monitoramento do impacto dos programas de combate à $\mathrm{FL}$, foi apresentado um modelo de xenomonitoramento produzido a partir dos resultados de um estudo multicêntrico, o qual foi conduzido para avaliar o uso da técnica de PCR em mosquitos. Para esse monitoramento, é definida uma área sentinela com 100 domicílios selecionados de forma aleatória, onde deverão ser coletados 10 mosquitos fêmeas ingurgitadas, por domicílio (xenomonitoramento), totalizando 1.000 mosquitos por área. Desse total, 700 mosquitos deverão ser analisados pela técnica de PCR e 300 por dissecção. A adaptação desse modelo de monitoramento da doença, como instrumento a ser implantado em Belém, deverá ser avaliada posteriormente, por parte dos técnicos presentes no Workshop.

\section{COMENTÁRIOS}

A Organização Mundial de Saúde não definiu os parâmetros necessários para certificar que a transmissão de FL está interrompida em um foco endêmico. Apesar disso, os técnicos reunidos em Belém, diante da quantidade e qualidade de dados apresentados, julgaram que havia suficiente evidência para assegurar que houve a interrupção da transmissão no foco de Belém. Essa interrupção ocorreu possivelmente em decorrência de um consistente programa de combate à doença sustentado por várias décadas, fundamentado na investigação parasitológica massiva da população e tratamento seletivo dos casos positivos, além do acompanhamento dos indivíduos infectados até a remissão de sua parasitemia e melhoria das condições ambientais (principalmente saneamento básico). E ainda, porque as ações de combate à doença se beneficiaram do controle de vetores dedicado a outras endemias.

Até aquele momento não se detectaram casos de infectados por FL nos municípios contíguos à Belém. Entretanto, enfatizouse que a migração pode oferece risco, embora pequeno, de reintrodução de FL. Isso porque muitos dos fatores ambientais que favoreceram anteriormente a instalação da endemia permaneciam presentes, sendo então necessária a manutenção de uma vigilância epidemiológica (VE), mínima. 0 modelo de VE a ser adotado será definido em outro momento, entretanto deverá estar apoiado no xenomonitoramento.

Considerou-se o foco de FL de Belém eliminado. Por esse motivo, propôs-se a elaboração de um documento de revisão de todas as informações relativas àquele foco, a ser encaminhado à OMS, solicitando o reconhecimento individualizado da eliminação deste foco. Se aceito, os resultados de Belém representariam um passo à frente na definição dos indicadores de interrupção da transmissão da FL.

\section{RECOMENDAÇÕES}

1. Elaborar um dossiê sobre o foco de FL de Belém a ser encaminhado à OMS até o segundo semestre de 2006.

2. Elaborar esse dossiê tendo como referência o modelo de verificação da situação epidemiológica adotado pelos chineses e adaptados pela OMS.
3. Por meio desse dossiê, solicitar à OMS o reconhecimento da interrupção da transmissão da FL em Belém, independente da situação das demais áreas do país.

4. Formar um grupo de trabalho para elaborar esse dossiê, constituído pelos técnicos presentes.

5. Instituir como instrumentos de vigilância epidemiológica póseliminação o monitoramento vetorial, xenomonitoramento.

6. Implantar o xenomonitoramento após a definição de um modelo, o qual deverá ser definido pelos técnicos da SVS, CPqAM e UFAL, presentes no workshop, levando em conta os critérios apresentados pelo Dr. Dave Chadee.

7. Manter as triagens hemoscópicas programados pela Secretaria Municipal para o ano de 2005 e também inquéritos hemoscópicos em municípios limítrofes à Belém.

\section{RESUMO DOS AVANÇOS ATÉ 2007}

As triagens hemoscópicas foram interrompidas na cidade de Belém em 2006. Estão em processo de conclusão inquéritos hemoscópicos em município próximos à Belém. Os resultados persistem negativos. 0 dossiê foi enviado à OPAS em outubro de 2006, encontra-se traduzido para o inglês e em processo de análise. 0 xenomonitoramento em Belém será implantado em 2008.

\section{PARTICIPANTES DO WORKSHOP}

Abraham Cezar de Brito Rocha (Serviço de Referência Nacional em Filariose/CPqAM - Recife, PE)

Ana de Nazaré Martins da Silva (Universidade Federal do Pará/UFPA - Belém, PA)

Ana Maria Aguiar dos Santos (Serviço de Referência Nacional em Filariose/CPqAM - Recife, PE)

Ana Moreira dos Santos (Secretaria Municipal de Saúde - Belém, PA)

Celsa Sampson (Organização Pan Americana de Saúde Brasil)

Dave Chadee (University of West Indian/Trinidad y Tobago)

David Addiss (Center of Disease Control - USA)

Eliana Maria Maurício da Rocha (Universidade Federal de Alagoas/UFAL - Maceió, AL)

Gerusa Dreyer (Organização Não Governamental Amaury Coutinho - Recife, PE)

Habib Fraiha Neto (Universidade Federal do PA/UFPA - Belém, PA)

Helen Abreu Freitas (Ministério da Saúde - Brasília, DF)

João Batista F. Vieira (Ministério da Saúde - Brasília, DF)

Leôncio Nazaré Pimentel (Secretaria Municipal de Saúde - Belém, PA)

Maria Aparecida Figueiredo (Secretaria Estadual de Saúde da Bahia - Salvador, BA) 
Raimundo Cândido Rocha (Secretaria Municipal de Saúde - Belém, PA)

Raimundo Nonato Maranhão (Secretaria Municipal de Saúde - Belém, PA)

Reinaldo F. Braun (Secretaria Municipal de Saúde de Belém, PA) Simone Valéria Costa Pereira (Ministério da Saúde - Brasilia, DF) Walquíria Cristina Viana (Secretaria Municipal de Saúde - Belém, PA)

Walter Wanderley Amoras (Universidade Federal do Pará - Belém, PA)

Zulma Maria Medeiros (Serviço de Referência Nacional em FilarioseCPqAM - Recife, PE)

\section{REFERÊNCIAS}

1. Braun RF, Rocha RC, Palhano RN, Vieira JBF, Fontes G, Amoras WW. Avaliação da Transmissão da infecção pela Wuchereria bancrofti em Belém_PA pelo método de imunocromatografia para detecção de antígeno. Apresentação em tema livre no XL Congresso da Sociedade Brasileira de Medicina Tropical, realizado no período de 07 a 11 de março de 2004, Aracaju - Sergipe, Brasil. Vol. 37: suplemento I, 2004.

2. Fontes G, Braun RF, Fraiha Neto H, Vieira JBF, Padilha AS, Rocha RC, Rocha EMM. Filariose linfática em Belém, Estado do Pará, Norte do Brasil e a perspectiva de eliminação. Revista da Sociedade Brasileira de Medicina Tropical 38: 131-136, 2005.

3. Fundação Nacional de Saúde. Gerência de Endemias Focais. Coordenação de Controle de Doenças Transmitidas por Vetores. In: Programa de Eliminação da
Filariose Linfática no Brasil, - 1997. Brasília -DF, Ministério da Saúde, Brasília, 1997.

4. Gyapong JO, Webber RH., Morris J, Bennett S. Prevalence of hydrocele as a rapid diagnostic index of lymphatic filariasis. Transactions of the Royal Society of Tropical Medicine and Hygiene 92: 40-43, 1998.

5. Medeiros Z, Gomes J, Béliz F, Coutinho A, Dreyer P, Dreyer G. Screening of army soldiers for Wuchereria bancrofti infection in the metropolitan Recife region, Brazil: implications for epidemiological surveillance. Tropical Medicine and International Health 4: 499-505, 1999.

6. Medeiros, ZM, Braun R, Rocha A, Costa J, Quaresma J, Palhano R, Candido R, Bonfim C. Indicador sintético de risco: uma estratégia espacial usada nas áreas sobre controle de filariose. Apresentado no formato de pôster no $8^{0}$ Congresso Brasileiro de Saúde Coletiva e $11^{0}$ Congresso Mundial de Saúde Pública, no período de 21 a 25 de agosto de 2006, Rio de Janeiro-RJ, Brasil, 2006.

7. Rachou RG, Deane LM. Filarioses humanas no Brasil. Conhecimento atual de sua distribuição geográfica e transmissão. Revista Brasileira de Malariologia e Doenças Tropicais 6: 377-387, 1954

8. Rocha A, Braun RF, Quaresma J, Costa J, Aguiar-Santos A, Freitas H, Bonfim C, Dias L, Oliveira C, Ault S, Medeiros Z. Inquérito antigênico da Filariose Bancroftiana em Belém do Pará. Verificação da ausência de infecção por Wuchereria bancrofti - o caso Belém do Pará. Revista da Sociedade Brasileira de Medicina Tropical 38 (supl I): 475-476, 2005.

9. Tropical Disease Research News. TDR News. Four TDR diseases can be "eliminated". Tropical Disease Research News 49: 1-8, 1996.

10. World Health Organization. Elimination of Lymphatic filariasis as a Public Health Problem. WHA (World Health Assembly), Geneva, p. 50.29, 1997.

11. World Health Organization. Preparação e Implementação de um Plano Nacional para a Eliminação da Filaríase Linfática, 2000

12. World Health Organization. Control of Lymphatic Filariasis in China, 2003.

13. World Health Organization. Monitoring and epidemiological assessment of the programme to eliminate lymphatic filariasis at implementation unit level, 2005 . 